\title{
ESTOQUE, OFERTA E USO DA INFORMAÇÃO: REFLEXÕES SOBRE UM RECURSO ESTRATÉGICO PARA O DESENVOLVIMENTO DO SETOR PRODUTIVO
}

\author{
Celeste Aída Sirotheau Corrêa JANNUZZI ${ }^{1}$
}

\begin{abstract}
RESUMO
Trata-se de uma retrospectiva histórica sobre o empenho da humanidade em estocar conhecimento, contextualizada nos aspectos culturais de cada periodo. Discute-se a oferta da informação sob o enfoque de uma produção contínua de conhecimento, enfatizando as especializações que resultam na diferenciação dos estoques e na oferta de diferentes tipos de informação. Faz-se um reflexão sobre o uso da informação na indústria, destacando-se diversas questões relacionadas aos obstáculos e otimização desse processo no desenvolvimento do setor produtivo.
\end{abstract}

Palavras-chave: informação; conhecimento; indústria; competitividade.

\begin{abstract}
It is a historical retrospective on humanity's interest in stocking knowledge, contextualized in the cultural aspects of each period. The supply of the information is discussed under the focus of a continuous production of knowledge, emphasizing the specializations that result in different kinds of stocks in the supply of different types of information. There is a reflection about the use of information in industry, highlighting several issues related to obstacles and to the otimization of this process in the productive area.
\end{abstract}

Key words: information; knowledge; industry; competitiveness.

\section{INTRODUÇÃO}

Os serviços de informação para empresas, ou outras organizações com o mesmo fim, são atividades que vem proliferando significativamente nas duas últimas décadas, seja no Brasil ou em outros países. Tal fato vem sendo alavancado pela necessidade de tornar as empresas cada vez mais competitivas, através de ações como, segundo Vieira (1996), a de adequação às mudanças tecnológicas e práticas comerciais que se sucedem em tempos cada vez mais curtos.

A importância dos serviços de informação para empresas está relacionada à crença de ser a informação o insumo estratégico para a competitividade. Mas essa forma de entendimento é parte de uma realidade mais abrangente onde a informação e o conhecimento representam desenvolvimento e evolução para toda a sociedade.

1. Mestre em Biblioteconomia pela Pontifícia Universidade Católica de Campinas. Doutoranda em Ciência da Informação e Documentação, na Escola de Comunicação e Artes da Universidade de São Paulo. Professora da Faculdade de Ciências Econômicas, Administrativas e Contábeis da Pontificia Universidade Católica de Campinas. 
A construção desse pensamento data de tempos remotos e, de acordo com os aspectos culturais de cada período vivenciado pelo homem, vai tomando proporções diferenciadas através da valorização do saber como um bem da humanidade. O conhecimento passa a representar a evolução do homem no tempo e a continuidade de suas conquistas para o progresso; a informação assume responsabilidades sobre isso.

\section{RETROSPECTIVA HISTÓRICA}

Wersig (1993) relata que, nos tempos antigos, o conhecimento era transmitido entre os indivíduos verbalmente, o que atribuía um caráter muito pessoal e restrito ao processo. Com a invenção do sistema de escrita, esse conhecimento passou a ser registrado e nessa nova forma de armazenar e transmitir conhecimento, McGarry (1999) ressalta que muito se deve aos scriptoria monásticos, que em seu tempo tinham a função de copiar textos.

Apesar da escrita agregar, conforme Tálamo (1997), duas características importantes como a disponibilidade e a permanência do conhecimento, ainda assim, ela se constituía como domínio de alguns - aqueles que sabiam ler - e que transmitiam oralmente aos outros o conhecimento que obtinham na leitura. Desse modo, por ser domínio de poucos, o saber constituía-se como sinônimo de poder entre indivíduos e povos. A biblioteca de Alexandria é apontada por McGarry (1999) como um exemplo dessa forma de soberania, pois era o produto de uma força de ocupação, na qual se almejava reunir todo o conhecimento do mundo.

Mesmo como domínio de poucos, o saber começa a tomar novas perspectivas através de iniciativas importantes sobre o armazenamento e transferência do conhecimento. Nesse contexto, destaca-se a contribuição da Universidade de Paris, no século XII, originária de uma escola monástica e constituída como um centro cultural, que, segundo McGarry (1999, p. 114), tinha o papel de "conciliar o cristianismo com o pensamento filosófico grego e gerava uma nova literatura profissional que ultrapassava em grande medida os escritos medievais antigos."

McGarry (1999) ressalta que o bem sucedido desempenho da Universidade revelou a necessidade de se ter livros para os estudantes. Tal situação promoveu o comércio de livros, através de copistas, leigos, que tentavam atender a demanda. Para contornar essa situação estabeleceu-se a condição de empréstimos dos livros que estariam de posse da universidade. $\mathrm{O}$ autor aponta a decisão como o início da função de referência e empréstimo, embrião das atividades exercidas, atualmente, pelas bibliotecas unidades de informação.

Após a invenção de Gutenberg, no século XV, a humanidade vivenciou o volume crescente de livros, propiciado, conforme Chartier (1998), pela evolução das técnicas de produção - manual, monotipo, linotipo, etc., culminando com a industrialização da impressão. Essa superprodução de textos (livros, jornais, periódicos, etc.) distanciou, cada vez mais, os ideais da biblioteca de Alexandria, pois agravou as dificuldades de armazenagem em espaços delimitados.

Foi no século XVII que se concebeu o que pode ser considerado como os primeiros conceitos sobre biblioteca, da forma como é compreendida hoje. Coelho Neto (1997) relata que Gabriel Naudé, em 1644, através de sua obra intitulada Advis pour dresser une bibliothèque (Conselhos para formar uma biblioteca) refere-se à biblioteca como uma instituição necessariamente pública - aberta a todos que interessassem - e universal - por conter todos os autores que tivessem escrito sobre diversos assuntos relacionados ao ser humano, como artes e ciências.

$\mathrm{O}$ autor ressalta que a orientação apresentada no trabalho de Naudé para a admissão das obras na biblioteca baseava-se no critério da utilidade que essas poderiam ter para a o público em geral. Uma outra orientação relevante nesse seu trabalho era a consciência dos limites em se colecionar todos os 
livros existentes no mundo, para tanto, Naudé propunha em admitir na biblioteca catálogos que informavam aos interessados onde achariam a obra que buscavam, caso esta não fosse oferecida no local.

Conforme observação de Coelho Neto, o entendimento de Naudé, para a época, se contrapunha fundamentalmente às práticas existentes, relacionadas aos critérios de seleção e uso das obras literárias e de artes. Os modelos adotados na primeira metade do século XVII idealizavam a biblioteca como um retiro, à margem das atividades domésticas e públicas; ou como um espaço, de curiosidades e obras seletas, concretizado principalmente por colecionadores que valorizavam a raridade e o luxo das obras em detrimento do seu conteúdo; ou, ainda, como a concepção jesuítica que selecionava apenas os livros cristãos, expurgando as obras consideradas heréticas, profanas ou heterodoxas.

Assim, o modelo de biblioteca, proposto por Naudé, revela-se como uma inovação das práticas até então adotadas, propiciando, conforme Coelho Neto (1997:77), um distanciamento "da idéia tradicional da coleção de opiniões de autoridades reconhecidas". Sua orientação sobre a importância de se selecionar obras consideradas úteis para a produção do conhecimento foi uma contribuição significativa para os dias de hoje.

Dentro de um contexto histórico, observa-se que o modelo de Naudé foi proposto em um momento de grande relevância na história da humanidade, uma fase em que se vivencia a valorização daquilo que faz do homem um homem - a razão. Essa nova postura sobre o saber determina um início significativo para uma volumosa produção de conhecimentos. A fundamentação dos fatos através da razão leva o homem a buscar a ruptura de idéias medievais explicações teológicos para todos os acontecimentos - a favor de uma objetividade que o levasse ao entendimento dos fenômenos e leis da natureza. O Humanismo foi o movimento representativo dessas idéias.

Apesar desse movimento em prol da razão, Coelho Neto (1995) revela que, no século XVII, a ruptura dos estudos entre a ciência e a religião, assu- mida por algum proponente, ainda implicava, por parte da igreja, em condenações à fogueira. Mas as idéias humanistas ganham força e adeptos, contribuindo para o abandono das explicações teológicas. Os estudos voltados para o homem e a natureza, através da experimentação e da dedução, propiciaram o progresso das Ciências. Assim, é no contexto desse fortalecimento que o racionalismo dá origem, no século XVIII, ao movimento Iluminista que com seu projeto da modernidade propõe, de acordo com Coelho Neto (1995:20), determinar “os campos distintos em que o pensamento e a ação poderiam exercitar-se: a fé de um lado, a verdade (da ciência) de outro, o comportamento em seus circuitos próprios e a arte por sua conta".

O iluminismo propicia a especialização do conhecimento e da expressão. O projeto da modernidade, de acordo com o autor, se firma ao longo do século XIX através de conquistas como a Revolução Industrial, de novos pensamentos sociais (como os apresentados por Karl Marx), do início de estudos como os da psicanálise e, no início do século XX, a revolucionária teoria proposta por Albert Einstein sobre o tempo e o espaço-a Teoria da Relatividade.

Nesse novo cenário de produção das ciências, o conhecimento especializado contribui para um volume crescente de dados/ informações e, para tanto, os princípios de organização do conhecimento proposto por Naudé confirmam seu valor e a humanidade promove o armazenamento dessa conquista.

\section{O ESTOQUE, A OFERTA E A DEMANDA DA INFORMAÇÃO}

$\mathrm{Na}$ busca pelo domínio e difusão do saber, McGarry (1999) ressalta que, então, a sociedade propicia o surgimento de diversos tipos de bibliotecas (governamentais, universitárias, escolares, industriais, etc.), todas com o intuito de organizar e armazenar informações para serem usadas. A multiplicação e a diversificação das unidades de informação são, naturalmente, uma conseqüência da necessidade de se estocar a produção crescente de conheci- 
mentos provenientes do racionalismo aplicados às ciências.

Na evolução dessa produção, a diversificação apresentada nas unidades de informação também se estende à informação propiciando sua classificação em diversos tipos ou categorias, a fim de facilitar tanto o processo de estocagem, como a organização da própria informação. Assim, nos dias atuais, é possível se fazer uso de denominações como: informação científica, informação tecnológica, informação estatística, informação para negócios, informação de mercado, etc.

Frente à variedade de informações produzidas continuamente nos diversos nichos da sociedade é possível deduzir que os estoques dessas informações se tornaram e ainda se tornam cada vez maiores. A esse fator de produção do conhecimento, acrescenta-se ainda, como contribuição ao aumento dos estoques nas unidades de informação, a necessidade de atualização dos acervos que, segundo Barreto (1994), são regidos por critérios de qualidade, novidade e abrangência das informações geradas.
Os estoques de conhecimento são idealizados e formatados para serem ofertados. Essa oferta, por sua vez, se configura através de uma demanda a ela atribuída. É a busca pelo domínio do saber. Mas o que se observa, na realidade, é que o conteúdo dessa oferta é inversamente proporcional àquele requisitado pelos usuários potenciais. Essa é uma questão que Barreto (1999) ilustra de forma brilhante quando relaciona a demanda e a oferta de informação com o estudo da pirâmide das necessidades humanas, proposto por Maslow ${ }^{2}$.

No contexto desse estudo, Barreto analisa comparativamente a pirâmide de Maslow com uma outra pirâmide, proporcional à primeira, porém invertida, representando os estoques de informação (vide figura 1). Em sua análise, o autor demonstra a preocupante relação das necessidades de informação com os estoques existentes, revela a grande extensão dos estoques destinados a um grupo seleto, porém pequeno, de receptores contrapondo a uma oferta reduzida de informação utilitária destinada a uma demanda potencialmente maior.

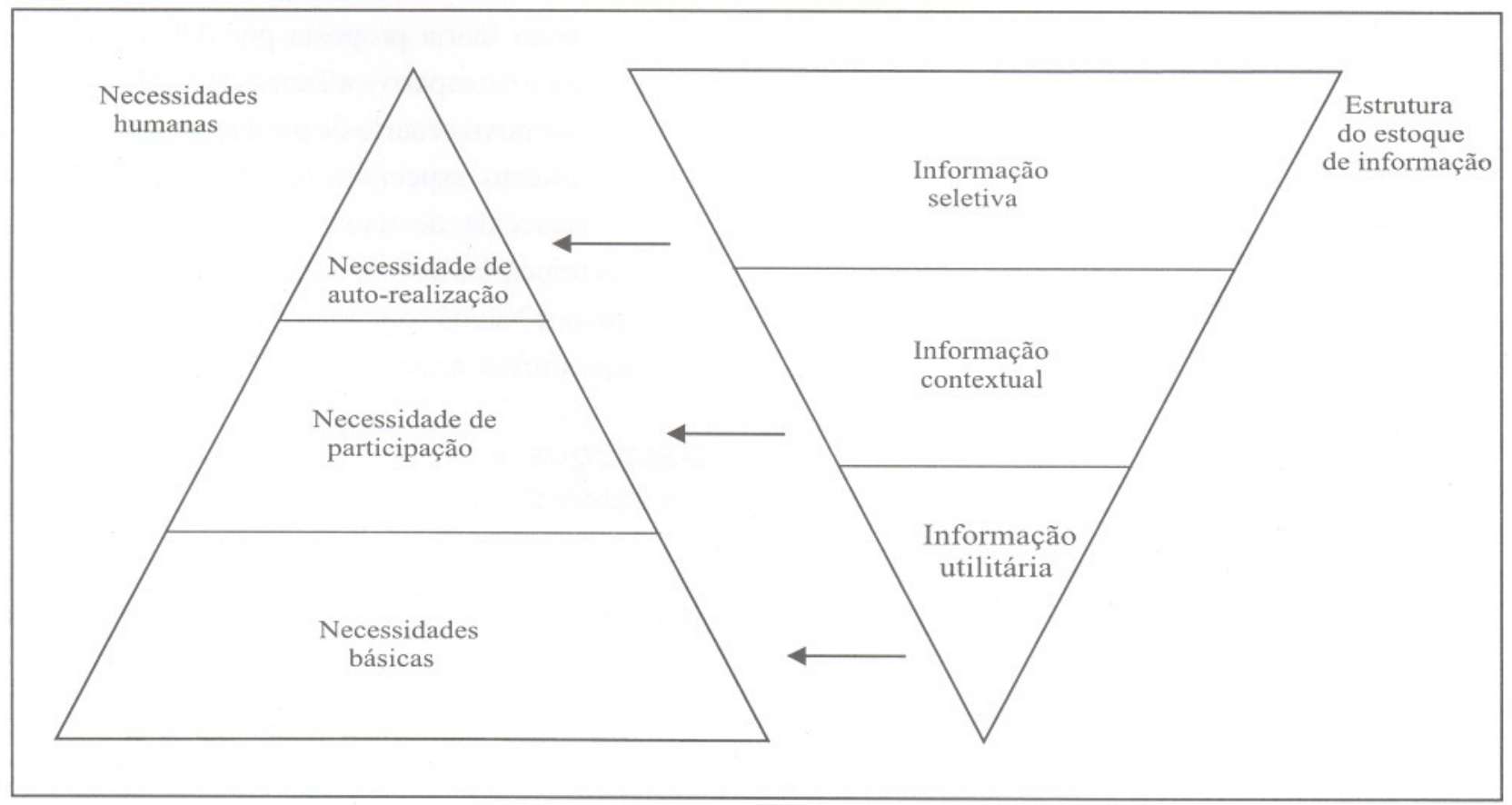

Figura 1. Representação do estoque de informação (segundo Barreto, 1999).

FONTE: BARRETO, A. de A., 1999. p.6.

2. MASLOW, A.H. Motivation and Personality. New York : Harper, 1970. (Fonte utilizada por Barreto, 1994). 
Em seu estudo, Barreto observa que as diferenças apresentadas na oferta e demanda das informações ocorrem tanto em termos quantitativos como, também, qualitativos e explica a estrutura de estoque de informação, ilustrado pela pirâmide, da seguinte forma:

- Informação seletiva - é aquela requisitada por indivíduos ou um pequeno grupo que, realizados nas necessidades básicas e participativas na sociedade, utiliza a informação para potencialização do seu conhecimento;

- Informação contextual - é a informação requisitada por indivíduos ou grupos que, satisfeitos em suas necessidades básicas, buscam esse tipo de informação como garantia de permanência para os diversos contextos dos quais participa - profissional, comunidade, etc.

- Informação utilitária - é aquela informação utilizada para suprir necessidades básicas de indivíduos ou grupos. Esse tipo de informação, conforme o autor, caracteriza-se por responder a questões relacionadas a alimentação, habitação, vestuário, saúde, educação etc.

$\mathrm{Na}$ representação das necessidades versus estoque de informação, proposta pelo autor, pode-se observar que uma demanda potencial de informações utilitárias ainda está por ser atendida e muitas podem ser as justificativas para essa constatação, entre elas, a relevância estabelecida por aqueles que decidem o que deve ser lido.

Barreto (1994) descreve a situação atual de busca pelo conhecimento como um modelo, no qual a oferta de informação é que determina a demanda. A oferta é estruturada a partir de prioridades estabelecidas por corporações públicas e privadas, que, segundo o autor, embora não possam determinar ao indivíduo o que este deve pensar, elas podem induzi-lo ao que lhes interessa. Sob a ótica dessa forma de atuação, observa-se, por muitas vezes, a presença de figuras que Coelho Neto (1997:78) denomina de diretor de leitura e de orientador cultural, que, conforme o autor, são representados por pessoas que "decidem, não apenas o que os outros devem ler, mas que os outros simplesmente devem ler".

Essa constatação é uma realidade nas práticas de oferta de informação, porém não necessariamente, pelo menos em um primeiro momento, prejudicial. Tomando-se por base o histórico na estruturação e organização do conhecimento, essa postura seria um elemento alavancador da difusão do saber entre os membros de uma sociedade, com a finalidade de prover e orientar as informações entendidas como relevantes a uma necessidade.

Assim, é sob critérios de prioridades políticas, econômicas e sociais, que o estoque, a oferta, as diversas unidades de informação foram sendo formatadas para serem usadas pela sociedade. Observa-se, por exemplo, dentro desse contexto, aquelas unidades de informação hoje estabelecidas como serviços de informação para empresas, cujo objetivo é o de oferecer subsídios para a capacitação competitiva das empresas.

Como exemplo no Brasil, aponta-se a criação da Rede de Núcleo de Informação Tecnológica do PADCT $^{3}$, cuja estrutura, de acordo com Vieira (1996), teve seu embrião na política governamental aplicada à informação, na década de 70 (séc. XX). Visando a implantação de serviços de informação de apoio à indústria, a Rede de Núcleos constitui-se então, em grande parte, por instituições de pesquisa, laboratórios, universidades e organizações representativas do setor produtivo, que se estabeleceram com apoio direto de suas unidades de informação - bibliotecas. Oficializava-se, assim, a informação como insumo para a capacitação das empresas nacionais e as unidades de informação como provedoras dessas informações.

Os tipos de informação oferecidos por essas unidades podem ser caracterizados, segundo a classificação proposta por Barreto (1999), como contextual e/ou seletiva, o que implica dizer que ela,

3. Programa de Apoio ao Desenvolvimento Científico e Tecnológico. 
em volume considerável, existe em estoque e está sendo ofertada. Mas, se essa afirmação for uma realidade, por que ainda se declara que existe carência de informações nas empresas brasileiras?

A resposta a essa questão pode estar fundamentada no fato de que, apesar da expansão das bibliotecas, em diversos setores da sociedade, apesar da expansão das unidades de informação especializadas para empresas, essas organizações, como depósito da memória da humanidade, tiveram, conforme McGarry (1999), seu papel truncado em prol da atividade de armazenamento e organização, revelando-se passivas na garantia da atividade de uso dos documentos armazenados.

É importante entender que a passividade referenciada pelo autor não condiz à falta de oferta de informação, pois como ele mesmo destaca houve um avanço significativo dos diversos formatos/técnicas para a formação desses estoques. O que McGarry aponta como um ato passivo é a falta de adequação da oferta de informação às condições de acesso de seus interessados, a fim de estimular o seu uso.

\section{USO DA INFORMAÇÃO: META PARA A AQUISIÇÃO DO CONHECIMENTO}

A produção contínua e volumosa de conhecimentos e o brilhante esforço efetuado na coleta, organização e disseminação das informações encontra nas tecnologias de informação, de acordo com McGarry (1999), um parceiro de grande valia na facilitação do acesso às informações. Mas, é importante ressaltar que, embora seja essa uma conquista relevante, adequar-se às condições de acesso tem um significado mais amplo, que se fundamenta, entre outros aspectos, no formato e conteúdo das informações. Formato, no sentido de se tornar inteligível ao usuário. Conteúdo, no sentido de despertar o interesse e responder às necessidades desse usuário.

Sobre esse aspecto, Barreto (1994:5) revela que a desproporção entre os estoques de informação e o seu uso se configura "pelas competências contextuais e cognitivas dos habitantes de realidades diferenciadas", que se apresentam como usuários reais e/ou potenciais desse estoques.

Essa é uma preocupação que pode ser evidenciada nas palavras de Tálamo (2000) sobre os usuá- rios do setor produtivo, quando ressalta que, no mundo, existe informação científica suficiente para solucionar os muitos problemas técnicos enfrentados pelas indústrias, mas que estas não conseguem ter essa informação, provavelmente porque seu formato está distante das condições de percepção e assimilação desses usuários potenciais.

Inúmeras são as informações de interesse dos usuários industriais. Muitas delas já estão disponibilizadas com fácil acesso, como através da Internet. Porém, o uso dessas informações por parte desses usuários não tem ocorrido satisfatoriamente. Sobre essa situação, podem existir causas diversas, entre elas, destaca-se por exemplo, aquela apontada por Freire (1991) quando se refere às questões terminológicas como uma das barreiras na comunicação da informação para as empresas, pois

"nem sempre usuários e agentes de informação usam o mesmo código de linguagem no processo de recuperação do conhecimento, podendo ocorrer, especialmente na transferência da informação para o setor produtivo, que a terminologia utilizada dificulte a compreensão da mensagem pelos usuários finais." (Freire, 1991:52).

Se os obstáculos apontados por Tálamo e Freire são uma realidade, como desejar que a informação se transforme em conhecimento para o setor produtivo? O conhecimento é o produto final a ser atingido através da transferência de informação. Mas, conforme Barreto (1994), esse conhecimento só se torna realidade, através da informação adequadamente assimilada, para que dessa forma possa modificar ou acrescentar significados no conhecimento prévio do indivíduo ou grupo.

Barreto (1999:374) afirma que "para intervir na vida social, gerando conhecimento que promove o desenvolvimento, a informação necessita ser transmitida e aceita como tal". Mas, ressalta que para alcançar esse intuito deve ser levada em consideração a diversidade de condições apresentada por cada indivíduo de uma comunidade, que conseqüentemente varia na sua capacidade de assimilação e transformação da informação em conhecimento. 
Assim, observa-se que a simples oferta de informação não se apresenta como garantia de que esta será usada e transformada em conhecimento.

\section{O CONHECIMENTO}

Apesar de sua importância ser reconhecida desde os tempos mais antigos, o conhecimento, na sociedade atual, vem apresentando mudanças significativas na sua forma de acesso, no seu valor de uso e aplicação. Wersig (1993) afirma que o papel conhecimento na sociedade vem se modificando ao longo do tempo, e com maior ênfase no início do século XX, como parte de uma mudança maior que alguns denominam de pós-modernismo.

$\mathrm{O}$ pós-moderno atribuído ao conhecimento se realiza, conforme Coelho Neto (1995), pelo fato deste último adotar, nos dias atuais, as mesmas premissas estabelecidas na Teoria da Relatividade apresentada por Albert Einstein, apontada como marco significativo da transição do período moderno para o pós-moderno. Tais premissas aplicadas ao conhecimento se traduzem através da transferência de informação que leva em conta a relação que subsiste entre os diferentes territórios do conhecimento, sem descaracterizar os procedimentos de cada um deles.

O período Moderno caracterizou-se pelo Humanismo que possibilitou a explicação dos fenômenos através da razão e pelo Iluminismo que contribuiu para a especialização das ciências. Todos esses movimentos imprimem mudanças expressivas em nossa sociedade que culminam em uma produção crescente e volumosa de conhecimentos. A humanidade se defronta com essas conquistas e somente consegue trabalhar esse universo admitindo o relativismo, ou seja, que não existe um conhecimento humano absoluto, tudo é relativo. Inicia-se o enfoque pós-modernista.

Wersig (1993) aponta quatro traços que considera como evidências da mudança relacionada ao conhecimento. O primeiro refere-se ao que caracteriza como despersonalização, no qual a transferência do conhecimento se torna cada vez mais impessoal, potencializado pelo advento das tecnologias de informação. O segundo, identificado pelo autor como credibilidade, é uma conseqüência do primeiro, pois a impessoalidade do conhecimento torna subjetivo o ato de identificar o que é e em qual conhecimento acreditar. O terceiro, Wersig se refere como fragmentação, o qual se apresenta como um resultado da divisão da ciência que foi ganhando autonomia em cada um dos segmentos. Por fim, o quarto traço, que o autor denomina de racionalização, implica na adoção de tecnologias diversas para reduzir a complexidade crescente do conhecimento.

No momento atual, esses traços do conhecimento, assinalados pelo autor, são percebidos inclusive, ou principalmente, no campo científico e acadêmico, no qual a oferta de informação - seletiva estaria sendo disponibilizada em proporções maiores que a demanda. O conhecimento científico, conforme Wersig, ganhou sua autonomia, personalizando cada vez mais sua linha de atuação. Essa divisão da ciência intensificou de tal forma a fragmentação do conhecimento que um mesmo campo da ciência também apresenta formas de atuação divergentes - autonomia intra-áreas, proporcionadas pelo uso de tecnologias de observação diferenciadas.

A fragmentação do conhecimento, presente no campo científico, também é vivenciada por outros setores da sociedade, como o setor produtivo. Em seu universo, as indústrias são identificadas por diferentes ramos de negócios e trabalham com diversos tipos de conhecimento, inclusive o científico. A necessidade de sempre incrementar melhorias nos produtos e serviços das indústrias, até mesmo para garantir sua sobrevivência em um mercado competitivo, contribuiu para que o volume e a complexidade do conhecimento exigido fossem atendidos por uma oferta de informação também especializada. Assim, é nesse contexto que surgem os serviços de informação para empresas, com o intuito de facilitar a identificação do conhecimento necessário para a solução dos problemas apresentados pela indústria.

A busca do conhecimento pelo setor produtivo, ou qualquer outro setor da sociedade, tem sido solicitada através de problemas que necessitam ser solucionados. A resposta a esses problemas é apresentada pelas informações obtidas através de atendimentos realizados pelas bibliotecas e sistemas de recuperação. Wersig (1993) refere-se à atuação das bibliotecas e sistemas de recuperação como aquelas 
que admitem que há algo como informação, de que se necessita, e suas preocupações de estudo procuram oferecer uma solução para um problema.

Wersig afirma que, aparentemente, nesse contexto, as soluções para problemas são consideradas simplesmente como um ato de reflexão ou como produtos de experiências práticas. Esse entendimento sobre o ato - como uma ação não científica - é refutada pelo autor, que considera que uma solução requisita uma analise detalhada do problema, para então propor abordagens alternativas e justificativas coerentes para as possíveis soluções. Uma abordagem científica.

Mas essa situação parece dar sinais de mudanças, porque, conforme o autor, já é possível observar que a maneira simplória de solucionar os problemas vem sendo superada por mudanças significativas no papel do conhecimento na sociedade. No campo científico observa-se que áreas como a da ciência da computação, que centrava a solução de seus problemas através de algoritmos, se confronta, atualmente, com a superação dessa definição por aplicações de computação não algorítmica, como as redes neurais e inteligência artificial.

Basicamente, a partir das colocações do autor, pode-se dizer que toda solução para os problemas, antes de se concretizar como solução, deve, na maioria das vezes, ser um ato de investigação, como a científica. Porém, na prática, o que se observa é que, embora a busca das respostas de um problema seja uma rotina já instituída nas bibliotecas e nos sistemas de recuperação, como nos serviços de informação para empresas, esse ato de resposta parece estar centrado nos mecanismos de recuperação das informações, sem o destaque necessário à solução do problema como aquisição de conhecimentos.

Ter como meta, na solução de problemas, a aquisição do conhecimento implica em compreender o usuário da informação. Foskett et alii (1980) ressalta que o sucesso dos serviços de informação, ou seja, da oferta e uso das informações, está fundamentado na necessidade de se conhecer o que passa na mente dos usuários. Assim, como primeiro passo para a solução de problemas aponta-se o entendimento do próprio problema. Kotler (1991:143) é categórico quando resgata um velho ditado que diz: "um problema bem definido já está meio resolvido".

O que, a princípio, pode parecer óbvio entender o problema - na realidade é uma tarefa bastante árdua. Os obstáculos a serem enfrentados nesse primeiro passo referem-se a um momento crítico relacionado à troca de informações entre indivíduos. Tal afirmação pode ser ilustrada através de um esquema apresentado por Whitaker (1998) sobre o ciclo de solução de problemas e o momento crítico (gargalo) da troca de informações (vide figura 2).

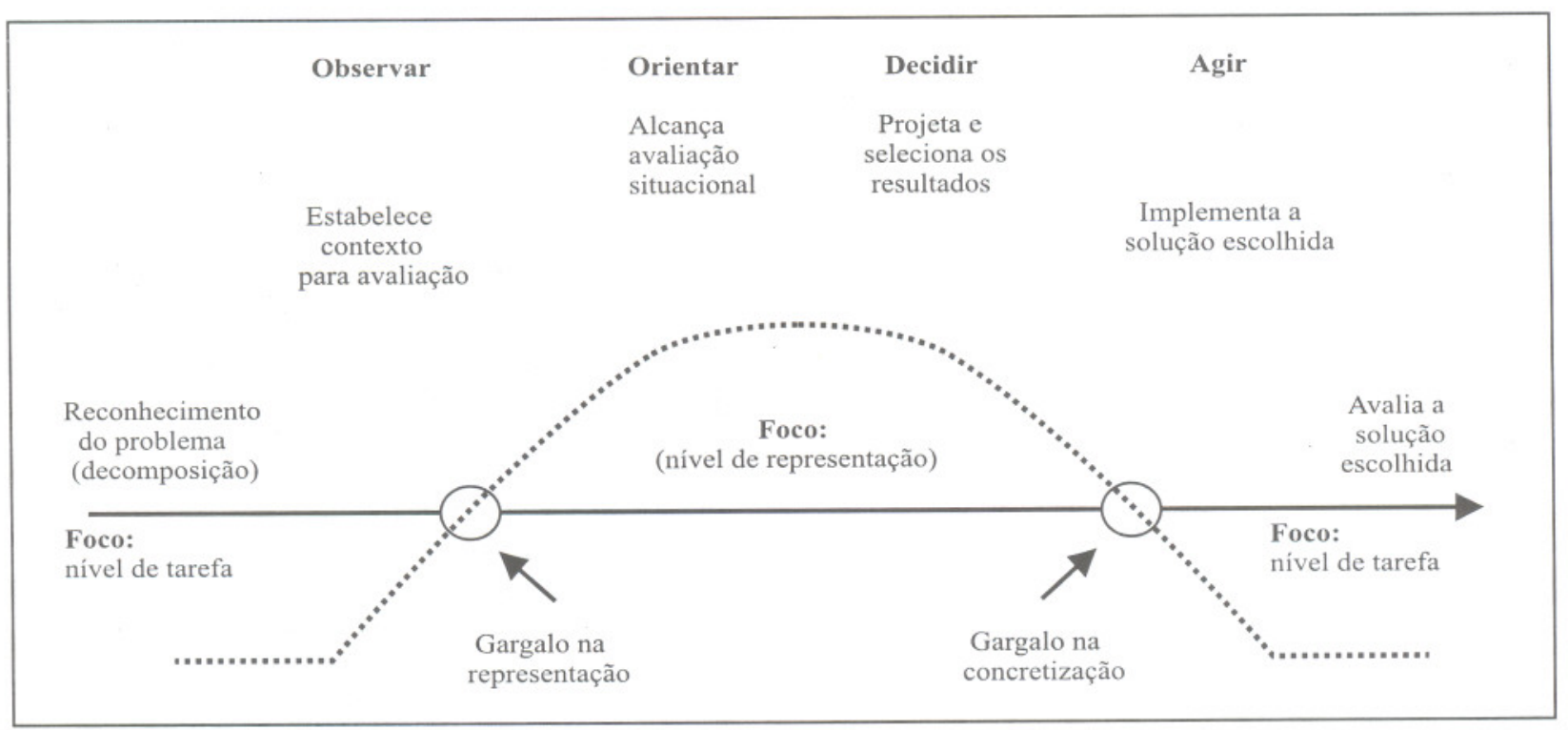

Figura 2. Aspectos informacionais de um ciclo de solução de problemas (segundo Whitaker: 1992,1994).

FONTE: WHITAKER, 1998:109. 
As dificuldades existentes na troca de informações entre indivíduos se estabelecem através do modelo mental de cada um. Modelo mental, de acordo com Kim (1998), é a visão que o indivíduo tem do mundo, incluindo o universo das compreensões explícitas (identificáveis) e implícitas (subjetivas). Assim, olhando por esse ângulo, é possível afirmar que, por muitas vezes, o problema exposto pelo usuário pode ser entendido sob outro enfoque pelo profissional da unidade de informação e, na outra ponta, as informações apresentadas ao usuário, como possíveis soluções do problema, também podem ser interpretadas de forma adversa àquela almejada pelo profissional da unidade de informação,

Como é possível observar ao longo do texto, a conquista do conhecimento pelo setor produtivo deve calcar inúmeros aspectos para que se torne efetivo - entendimento do problema, orientação metodológica na solução de problemas, formato adequado das informações, terminologia inteligível para o usuário, etc.

\section{O CONHECIMENTO E A INDÚSTRIA}

Quando se fala na oferta e no uso da informação para aquisição do conhecimento na indústria, implica dizer que a informação é um recurso que se torna cada vez mais necessário e urgente para subsidiar a tomada de decisões nas empresas brasileiras, visando a competitividade. Na dinâmica que envolve a globalização da economia, o poder da competitividade está centrado no acesso contínuo às informações estratégicas a respeito de mercado, barreiras técnicas, legislação, companhias, produtos, tecnologia, etc. Mas, nesse contexto, uma questão é formulada: qual é a informação que a indústria necessita e que pode ser transformada em conhecimento, a fim de torná-la competitiva?

O início dessa resposta pode ser estruturado no sentido inverso da pergunta. Assim, no primeiro momento, torna-se importante entender o signifi- cado de competitividade. Para Coutinho \& Ferraz, competitividade é

"a capacidade da empresa de formular $e$ implementar estratégias concorrenciais, que lhe permitam conservar, de forma duradoura, uma posição sustentável no mercado. "(Coutinho \& Ferraz, 1995:18).

Assim, analisando o exposto pelos autores pode-se dizer que para ser competitivo é necessário ter informação, pois somente com esse recurso é possivel formular estratégias bem articuladas com o ambiente que a empresa está inserida.

$\mathrm{Na}$ seqüência da pergunta acima, torna-se necessário entender o uso do conhecimento na empresa. De acordo com Kim (1998), a empresa busca o conhecimento como forma de incrementar sua aprendizagem organizacional - operacional (know-how) e conceitual (know-why). Assim, para sua aprendizagem, a empresa precisa explorar o conhecimento existente sobre suas atividades seja no ambiente interno, bem como do ambiente externo, e, para tanto, precisa também obter informações.

Cassarro (2001) revela que uma grande quantidade dessas informações é gerada dentro da própria empresa. Dessa forma, sob esse enfoque, pode-se dizer que para a obtenção desse tipo de informação a empresa, necessariamente, precisa se organizar internamente (coleta e tratamento dos dados, tecnologias de comunicação, etc.), de modo a permitir o fluxo interno das informações que produz.

Sobre as informações do ambiente externo, Cassarro aponta dois tipos: a) aquelas procedentes das organizações com as quais a empresa se relaciona (fornecedores, clientes, etc.); e b) aquelas que a empresa busca (sobre mercado, economia, etc.). A importância dessa última, é que ela permite que a empresa se intere do seu cenário atual, bem como, quando devidamente trabalhadas por especialistas econômicos, projete cenários futuros e estabeleça estratégias competitivas. 
As informações, que as empresas necessitam para gerar conhecimento, existem. Porém, o volume cada vez mais crescente de informações e o fato de se trabalhar com o conhecimento despersonalizado trazem à tona, de acordo com Tálamo (2000), a necessidade de seleção e credibilidade das informações, daí a importância das unidades e serviços de informação para empresas.

As indústrias precisam do conhecimento que está sendo gerado, a fim de incrementar sua aprendizagem e se tornarem competitivas. As unidades e serviços de informação oferecem as informações para esse fim. O que está faltando para formar esse elo?

\section{CONSIDERAÇÕES FINAIS}

Historicamente, o domínio do saber sempre esteve associado a um ato de poder. Atualmente, apesar de todo o avanço científico, tecnológico, social, etc. vivenciado pela sociedade, o saber, o conhecimento, ainda é o que determina o desenvolvimento das nações, sua soberania. Assim, referir-se ao fortalecimento da indústria brasileira é também se referir à busca da força do conhecimento.

O conhecimento está sendo constantemente produzido e seu estoque idealizado para a preservação dessa produção. A informação é o recurso provedor dessa conquista, mas somente o seu uso efetivo permitirá que, aquilo que está sendo ofertado aos usuários, se transforme em conhecimento. Observa-se que mesmo com o advento das tecnologias de informação, com acessos às fontes facilitados, com os avanços das técnicas de organização e recuperação das informações, o uso de informações relevantes para a gestão de negócios ainda não é uma realidade para uma grande maioria de usuários do setor produtivo brasileiro.

A resposta pelo uso ainda ineficiente das informações pode estar na formatação das informações, na identificação da linguagem utilizada no setor, no modelo mental desses usuários, etc. Muitas podem ser as respostas..., talvez uma única, a conscientização do próprio usuário do setor produtivo sobre como usar as informações... Mas, nesse momento, apenas uma constatação pode ser feita: a solução para o uso efetivo dessas informações não está alicerçada apenas na identificação das necessidades informacionais do setor produtivo, nem na oferta das informações, mas antes de tudo, como destaca Tálamo - já comentado anteriormente no texto - às condições de percepção e assimilação desses usuários.

\section{REFERÊNCIAS BIBLIOGRÁFICAS}

BARRETO, A. de A. Os destinos da Ciência da Informação : entre o cristal e a chama. Informação \& Sociedade: Estudos, João Pessoa, vol. 9, n. 2, pp. 371-382, 1999.

. A questão da informação. São Paulo em Perspectiva, São Paulo, vol. 8, n. 4, pp. 3-8, 1994.

CASSARRO, A.C. Sistemas de informações para tomada de decisões. 3. ed. São Paulo : PioneiraThomson Learning, 2001.

CHARTIER, R. A aventura do livro: do leitor ao navegador. São Paulo: UNESP, 1998, pp. 117-128.

COELHO NETO, J.T. Dicionário crítico de política cultural. São Paulo: Iluminuras, 1997. Biblioteca, pp. 76-79.

Moderno pós-moderno. 3. ed. São Paulo: Iluminuras, 1995. pp.13-39.

COUTINHO, L. \& FERRAZ, J. C. (Coords.). Estudo da competitividade da indústria brasileira. 3. ed. Campinas: Papirus; Editora da Universidade Estadual de Campinas, 1995.

FOSKETT, D. J. et al. A contribuição da psicologia para o estudo de usuários da Informação técnico-científica. Rio de Janeiro: Calunga, 1980.

FREIRE, I. M. Barreiras na comunicação da informação tecnológica. Ciência da Informação, Brasília, vol. 20, n. 1, pp. 51-54, jan./jun. 1991.

KIM, D.H. O elo entre a aprendizagem individual e a aprendizagem organizacional. In: KLEIN, D.A. A gestão estratégica do Capital Intelectual: recursos para a economia baseada em conhecimento. Rio de Janeiro: Qualitymark, 1998. Parte II, cap. 4. 
KOTLER, P. Administração de marketing. 2.ed. São Paulo: Atlas, 1992.

\section{McGARRY, K. O conceito dinámico da informacão:} uma análise introdutória. Brasilia: Briquet de Lemos/Livros, 1999. pp.111-142.

TÁLAMO, M. de F. G.M. Aula proferida na disciplina Formas de estruturação e mediação da informação institucionaliza, ministrada pelas Profas. Maria de Fátima Tálamo e Johanna W. Smit, no curso de Pós-Graduação do Departamento de Ciências da Informação e Documentação - CBD, na Escola de Comunicação e Artes - ECA, da Universidade de São Paulo - USP. São Paulo, 23 nov. 2000.

Linguagem documentária. São Paulo: APB, 1997. (Ensaios APB, 45).
VIEIRA, A. da S. Informação tecnológica no Brasil pós-PADCT. Ciência da Informação, Brasília, vol. 25, n. 1, pp. 59-75, jan./abril 1996.

WERSIG, G. Information Science: the study of postmodern knowledge usage. Information Processing \& Management, Great Britain, vol. 29, n. 2, pp. 229-239, 1993.

WHITAKER, R. Gerenciando o contexto nos processos de conhecimento da empresa. In: KLEIN, D.A. A gestão estratégica do Capital Intelectual: recursos para a economia baseada em conhecimento. Rio de Janeiro: Qualitymark, 1998. Parte II, cap.6 